\title{
CEREBRAL TUMOURS IN CHILDREN
}

\section{A PATHOLOGIGAL REPORT}

\author{
BY \\ RUBY O. STERN, M.D. \\ (Sebag-Montefiore Research Fellow at the Hospital for Sick Children, \\ Great Ormond Street.)
}

\begin{abstract}
Rapid advances in neurosurgery and recently acquired knowledge of the growth and spread of cerebral tumours based on their microscopical differentiation have given an impetus to the study of these tumours from divers aspects. The dictum that cerebral tumours are rare in children but are almost invariably malignant and inoperable has long been accepted. For this reason perhaps there have been few reports of late years from children's hospitals on the pathology of these tumours. With one or two exceptions the material recently presented on this subject has been derived from special neurological hospitals and clinics. New facts have emerged from some of these reports regarding the incidence and structure of cerebral tumours in children and a more hopeful note on prognosis has been sounded. It was therefore felt that an examination of the cerebral tumours at a large general hospital for children and particularly a study of their microscopy based on a modern classification might yield certain information. The results of this examination are presented in this paper.
\end{abstract}

\section{General considerations}

The investigation covered a period of fifteen years, from 1921 to 1935 . This period was taken in order to obtain as large a series of tumours as possible. Sections from specimens prior to 1921 were not available. Particulars of all cases diagnosed clinically as ' cerebral tumour' were obtained and whenever possible the topographical distribution and histological nature of the tumours were ascertained of those patients who died and on whom an autopsy was performed. If autopsy material was available frozen sections and blocks embedded in celloidin were cut. If only paraffin blocks were to be found then fresh sections were stained by a variety of methods. The stains used for the preparation of these new sections were iron haematoxylin with van Gieson's counterstain, Mallory's phosphotungstic acid haematoxylin and, in some cases, Anderson's victoria blue stain and Hortega's silver carbonate stains. In some of the earlier cases a diagnosis had to be made by examination of a section stained by the routine method of haematoxylin and eosin. In a few instances this was 
impossible. Sections were missing from a few cases and in these no diagnosis could be made as it was idle to speculate on the nature of the tumour from the description of its macroscopical appearance and futile to attempt to elucidate the previous microscopical diagnosis of 'sarcoma' or 'gliosarcoma.'

It is necessary to emphasize that only cases diagnosed clinically as ' cerebral tumour' are considered here. During a perusal of the postmortem records no cerebral neoplasms were encountered which had not previously been diagnosed, but a number of small tuberculomata were traced the presence of which had not given rise to symptoms of tumour. In these cases the cause of death was tuberculous meningitis. The question arose if these cases, in most of which the tuberculomata were only just visible macroscopically, were to be included in a report on ' cerebral tumours.' In other recent studies of cerebral tumours in children this has not been done and for this reason it was decided not to include such cases in this report. A note on these tuberculomata will appear elsewhere. Here are included only those tuberculomata in which a diagnosis of cerebral tumour was made - six in all-and in three of these a decompression operation was performed.

In the older literature on cerebral tumours tuberculomata were considered to be the most common tumour in childhood. Starr ${ }^{16}$, for example, found over 50 per cent. of his 300 cases of cerebral tumour in children were tuberculomata. It is not clear, however, if these all represented masses giving rise to the symptoms and signs of cerebral tumour or if they included the small tuberculomata discovered accidentally at post-mortem examination of cases of tuberculous meningitis. Garland and Armitage ${ }^{11}$ in their survey of intracranial tuberculomata (which included all tiny multiple tuberculomata found in the brain in tuberculous meningitis), concluded that tuberculomata constituted 60 per cent. of all intracranial tumours in children. This is only true if tiny masses present in the brain in certain cases of tuberculous meningitis are included in a classification of cerebral tumours. Van Wagenen ${ }^{17}$ stated that in 140 cases of cerebral tumour in patients under nineteen years of age only five (3.5 per cent.) had tuberculomata, whilst in ninety-eight cases of tuberculous meningitis macroscopical tuberculomata were present in nine $\left(9 \cdot 1\right.$ per cent.). Similarly Cushing ${ }^{8}$ in his series of 154 cases of cerebral tumour in children under fifteen years of age could find tuberculomata only in six ( 3.9 per cent.).

The frequency of intracerebral tuberculomata excluding those found accidentally in cases of tuberculous meningitis would therefore seem to be low. The figures in the present series, based on the same distinction, also reflect this low incidence.

\section{The incidence of cerebral tumours in children}

One hundred and two cases of cerebral tumour were diagnosed during the period under review. Of thirty-seven children in whom the diagnosis was made and who left the hospital, six were transferred to other hospitals (two subsequently had a tumour successfully removed at the London Hospital), three were reported as showing ' slight improvement' (two after a decompression); two were taken home by their parents; twenty were 
discharged ' in statu quo '; the condition of three was 'worse'; and in three cases no note was recorded on discharge. There were sixty-five deaths and autopsies were performed on sixty-two cases. The total number of post-mortem examinations performed during the same period was 2,808, so that cerebral tumours accounted for $2 \cdot 2$ per cent. of all autopsies. It would be valueless to give the apparent clinical incidence of these tumours calculated from the figures for total admissions to the hospital during the fifteen years as a large number of children were admitted for one day only for recovery from tonsillectomies or for dental treatment and therefore figures so calculated would convey a false impression of the incidence of cerebral tumour in relation to other diseases of childhood.

The autopsy figures were high compared with those of Wollstein and Bartlett $^{18}$ who were able to collect only nine cases of cerebral tumour in 4,563 autopsies (0.2 per cent.), at the Babies' Hospital, New York. The difference in these figures cannot be attributed to the fact which some observers have stated, that more cerebral tumours occur in older children. Critchley $^{7}$, for example, in reporting 125 cases in children under the age of fourteen out of 1,028 cases diagnosed as cerebral tumour at the National Hospital, Queen Square, found that only three occurred under three years of age, whilst Russell and Ellis ${ }^{13}$ in fifty-three verified cases of gliomata in children met with only twelve in the first five years of life.

In the present series (taking the 102 cases diagnosed), fifty-four-that is over half-occurred in children under the age of five years, and fortyeight between the ages of five and twelve years. Of the cases which came to autopsy there were thirty-five in the first five years of life and twentyseven between five and twelve years. The absolute age incidence is given in table 1. Certain points in this table should be mentioned. The first is the number of tumours which occurred in the first two years of life, fourteen, all of which came to autopsy and constituted over a quarter of those thus verified. Their pathological nature will be discussed later, but it may be remarked here that only two of the tuberculomata fell within this age

TABLE 1

Age incidesce. (ali. tumours).

\begin{tabular}{|c|c|c|c|c|c|c|c|c|c|c|c|c|}
\hline & $\begin{array}{l}0-1 \\
\text { Yk. }\end{array}$ & $\begin{array}{l}\text { 1-2 } \\
\text { Yte. }\end{array}$ & $\begin{array}{l}2-3 \\
\text { Yی. }\end{array}$ & $\begin{array}{l}3-4 \\
\text { Y u. }\end{array}$ & $\begin{array}{l}4-5 \\
\text { rk. }\end{array}$ & $\begin{array}{l}5-6 \\
\text { Y } 1 .\end{array}$ & $\begin{array}{l}6-7 \\
1 \cdots .\end{array}$ & $\begin{array}{l}7-8 \\
\text { YK. }\end{array}$ & $\begin{array}{l}\text { S-9 } \\
\text { Yк. }\end{array}$ & $\begin{array}{l}9-10 \\
\text { YR. }\end{array}$ & $\begin{array}{c}10-11 \\
\mathrm{YR} .\end{array}$ & $\begin{array}{c}11-12 \\
\text { YK. }\end{array}$ \\
\hline $\begin{array}{l}\text { All cerebral } \\
\text { tumours } \\
\text { diagnosed } \\
(102)\end{array}$ & 6 & 8 & 14 & 16 & 10 & 7 & 14 & 5 & 5 & 6 & 6 & 5 \\
\hline $\begin{array}{l}\text { Tumours } \\
\text { verified } \\
\text { post mortem } \\
(62) \\
\text { Unrerified } \\
(40 .)\end{array}$ & 6 & 0 & 6 & 8 & 5 & 6 & 10 & 2 & 2 & 4 & 4 & 3 \\
\hline
\end{tabular}


period. Another point which emerged from this table of age incidence was the early age at which most cerebral tumours occurred. Thirty out of the 102 were found during the age period two to four years, though of these fourteen were in the unverified clinical group. Taking the verified group separately, this age period shared the highest incidence with that of five to seven years (sixteen cases for each period). It is noteworthy that the incidence for each of the five years from seven to twelve was practically the same.

There was no appreciable difference in the sex incidence. Of the total number fifty-five were boys and forty-seven girls. Autopsies were made on thirty-seven boys and twenty-five girls, this proportion of boys to girls being slightly less than the proportion of boys to girls for all autopsies over the same period. (Males 57.84 per cent.; females $42 \cdot 16$ per cent., 1.37 to 1). Although there was no difference between the sexes in regard to the incidence of cerebral tumours in general, one particular type of tumour, the medulloblastoma, occurred nearly three times more often in boys than in girls. Cushing ${ }^{8}$ and Armour ${ }^{1}$ have previously remarked that this tumour appears to preponderate in boys; they gave the ratio of 3 to 1 .

\section{Topographical distribution}

Every writer on the subject has emphasized the essential difference in localization between cerebral tumours in children and in adults. In children the majority of tumours lie in the subtentorial region of the brain; in adults the proportion of tumours in this position is relatively small. Critchley ${ }^{7}$, whose series included patients up to the age of seventeen years, found that 47.2 per cent. of his 125 tumours occurred below the tentorium. Cushing ${ }^{9}$ in a critical review of the medulloblastomata reported that 70 per cent. of tumours in the first five years of life were subtentorial, whilst Armour ${ }^{1}$ declared that in his experience this figure obtained for the first decade but that after the age of ten the incidence of supratentorial tumours rose rapidly until at the age of fifteen equal numbers were found above and below the tentorium. In a large series of cases in children up to the age of fifteen years Cushing found that the proportion of subtentorial to supratentorial tumours was two to one.

In the present series the localization of the sixty-two tumours verified at autopsy was determined. The relative frequency of tumours above and below the tentorium agreed almost exactly with the figures given by Cushing and quoted above. In forty-one of the sixty-two cases the tumour lay below the tentorium and in nineteen it lay above. In two cases, both of tuberculomata, a large mass was present in the cerebellum and had been diagnosed during life, whilst small masses were present in the cerebral hemispheres, in one case in the right parietal lobe, in the other in the left frontal lobe. Multiple tumours were present in four other cases. In two 
of these they were all above the tentorium and in two all the tumours lay below it. One of the supratentorial cases was of particular interest. This was a tumour of both optic nerves and the chiasma with a separate tumour mass in the right frontal lobe. This case was shown during life at a meeting of the Neurological Section of the Royal Society of Medicine in 1924 by W. G. Wyllie and subsequently reported by him ${ }^{19}$. Another case which presented multiple tumours was one of extensive tuberculous disease in which a degenerating tuberculoma involved the whole of the basal nuclei on both sides, there being also a tuberculous mass in the left occipital lobe. Multiple tuberculomata were found in two other cases. In one, three tuberculomata were present in the cerebellum and one small mass in the floor of the fourth ventricle. In the other, the pons and cerebellum each contained one and in addition most of the lumbar region of the spinal cord was occupied by a caseous mass of degenerating tuberculous tissue.

The topography of the tumours is most simply expressed in tabular form (the six multiple tumours being excluded):-

\section{Distribution OF TUMOURS IN THE BRAIN.}

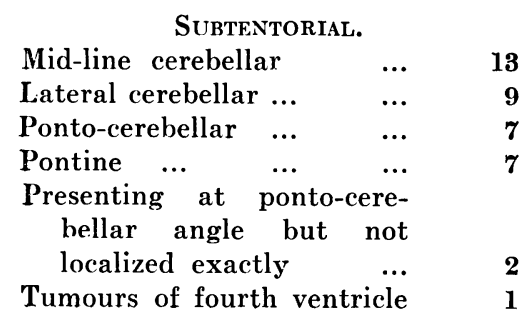

Supratentorial.

Frontal and frontal-parietal 4

$\begin{array}{lllll}\text { Parietal } \ldots & \ldots & \ldots & 1\end{array}$

$\begin{array}{llll}\text { Temporal } \ldots & \ldots & \ldots & \text { 2 }\end{array}$

$\begin{array}{lllll}\text { Occipital } & \ldots & \ldots & \ldots & \mathbf{2}\end{array}$

Basal ganglia $\quad \ldots \quad \ldots . \quad \ldots$

Suprapituitary $\quad \ldots \quad \ldots \quad \ldots$

Third ventricle $\quad \ldots \quad \ldots \quad 1$

$\begin{array}{lllll}\text { Midbrain } & \ldots & \ldots & \ldots & \text { 2 }\end{array}$

Crura cerebri $\quad \ldots \quad \ldots . \quad \ldots$

The absence of tumours of the pituitary region was surprising. Only one was present in the suprapituitary region. Cushing ${ }^{8}$ traced no less than twenty pituitary or suprapituitary tumours amongst his 154 cases under fifteen years of age and $\mathrm{Critchley}^{7}$ reported fourteen such tumours out of 125 cerebral tumours occurring below the age or seventeen years. It is of interest that there should be such an increase in the number of pituitary and suprapituitary tumours between the ages of twelve (which was the upper age limit of the present series) and seventeen years.

The vermis of the cerebellum was the commonest site of origin for a tumour. This observation merely confirms previous findings. In many cases the tumour remained localized to the vermis and involved neither lateral lobe. In other cases both the lateral lobes of the cerebellum and the pons were invaded. Other tumours, not arising in the vermis involved both the pons and one or both lokes of the cerebellum. These tumours were classified above as 'ponto-cerebellar.' Growths confined to one or other lateral lobe were recorded as ' lateral cerebellar.' The two tumours listed as 'presenting at the ponto-cerebellar angle' were difficult to localize with certainty. One was a haemorrhagic cyst which had burst, 
much brain tissue in the vicinity of the ponto-cerebellar angle being destroyed; the other was a tumour of the choroid plexus involving the ventricles which presented on the under-surface of the brain in the situation described.

Tumours of the cerebral cortex were relatively uncommon, forming only one-seventh of the total number. They were of interest chiefly on account of their histological structure.

\section{Histological differentiation}

The number of tumours available for histological study was fifty-five. No material or sections could be traced in seven cases. From the excellent description of the histology of one case in which the sections could not be found, the case of a tumour of the optic nerves and chiasma reported ${ }^{19}$ by Wyllie in 1924 there could be no doubt that this was a polar spongioblastoma. (The specimens and sections of an almost identical case were shown at a meeting of the Neurological Section of the Royal Society of Medicine in April, 1937, by the writer.)

The gliomata accounted for more than two-thirds of the tumours verified histologically. Forty-one of the fifty-four verified cases belonged to one of the sub-divisions of this group. The actual incidence was probably higher as four of the cerebellar tumours of which no sections were available were almost certainly gliomata.

The other tumours were six tuberculomata, four sarcomata (one of which was a melanotic sarcoma), two meningiomata, and one epithelioma of the choroid plexus. This preponderance of the gliomata confirmed other recent findings in children. Van Wagenen ${ }^{17}$ remarked that the gliomata rather than the tuberculomata represented 50 per cent. of cerebral tumours in children, whilst Blacklock ${ }^{6}$ made a histological examination of a hundred malignant tumours from all parts of the body which revealed no less than 20 per cent. as belonging to the glioma group. Cushing ${ }^{8}$ in his series of 154 cerebral tumours in children under the age of fifteen classified 116 as gliomata.

The classification of gliomata by Bailey and Cushing" according to their histogenesis has allowed a certain parallel to be drawn between the appearance of the tumour under the microscope and its clinical course. This follows the accepted principle that the more primitive the cells of which the tumour is composed the more malignant it is and the shorter will be the duration of life. In the nervous system, however, another cogent factor has to be considered, the situation of the tumour. A tumour may consist entirely of well-differentiated cells and be eminently suitable for complete surgical removal but it may be present in a position to which surgical access is imposskle, for example, deep in the pons or midbrain. The results of the histological examination of the present series of tumours clearly 
illustrates this point. Benign gliomata were as common as the malignant types but owing to the position of many of the benign forms surgical removal would have been out of the question. This was particularly evident in the pons, where six out of the seven tumours present in this region were benign astrocytomata. Owing to their situation deep in the pontine-tissues and

TABI,E 2.

POSITION OF HISTOLOGICAL TYPLS OF TUHOLR IN SCDTENTORIAL REGION UF BRAIN.

\begin{tabular}{|c|c|c|c|c|c|c|c|}
\hline & & & $\begin{array}{c}\text { MID-LINE } \\
\text { CEREBELIAR }\end{array}$ & $\begin{array}{c}\text { LATERAI } \\
\text { CEREBFLIAR }\end{array}$ & $\begin{array}{c}\text { PoNTO- } \\
\text { CERLBEILAR }\end{array}$ & Pontine & $\begin{array}{c}\text { FodRTH } \\
\text { VENTRICLE }\end{array}$ \\
\hline Medulloblastoma & $\cdots$ & $\cdots$ & 7 & 2 & 2 & 0 & 1) \\
\hline Glioblastoma .. & $\cdots$ & $\cdots$ & 0 & 2 & 1 & 1 & 0 \\
\hline Ependymoma ... & $\cdots$ & $\cdots$ & 2 & 0 & 1 & - & 1 \\
\hline Astrocytoma group & & $\ldots$ & 2 & 3 & 1 & 6 & 0 \\
\hline Tuberculoma & $\cdots$ & $\cdots$ & 0 & l & 0 & 0 & 0 \\
\hline Sarcoma & $\cdots$ & $\cdots$ & 1 & 0 & 0 & 0 & 0 \\
\hline
\end{tabular}

TABLE 3.

POSITION OF HISTOLOGICAL, TYPES OF TUMOUR IN SUPRATENTORIAI, HEGION OF TIIE IBRAIN,

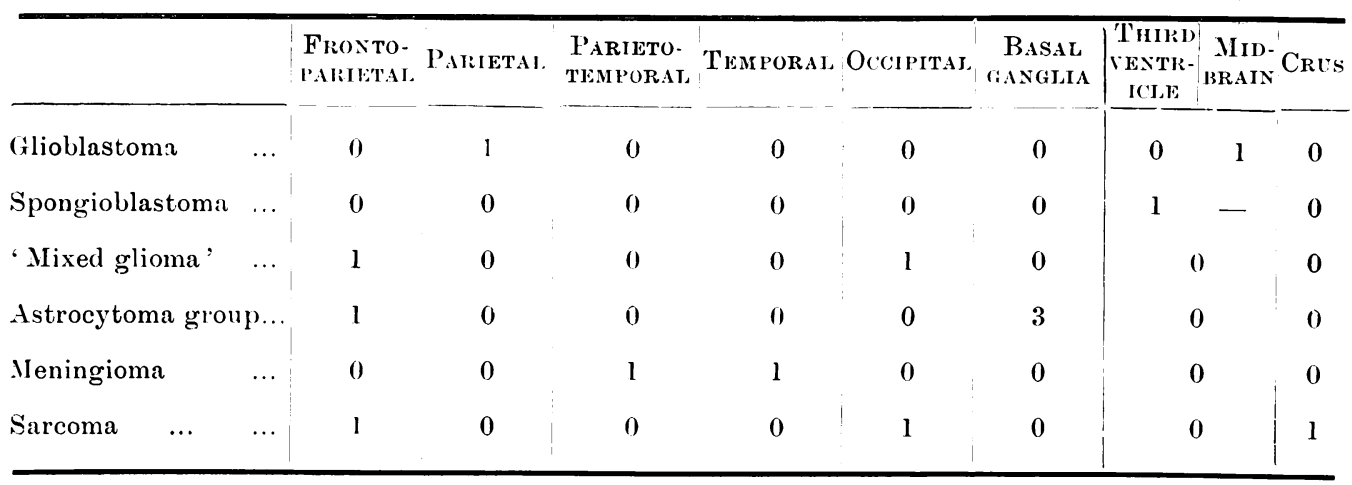

their close proximity to vital centres they were inoperable. Tables 2 and 3 give the distribution in the subtentoral and supratentorial regions of the brain of the histological types. The gliomata are listed in descending order of malignancy (multiple tumours are excluded as they have already been mentioned).

Certain features of the histology of these tumours merit comment. The first is the high incidence of the most benign form of glioma, the astrocytoma. This tumour consists of well-differentiated neuroglial cells with fibrillar processes which are demonstrable by special stains. The tumour varies in cellularity; some forms are practically acellular (astrocytoma fibrillare) whilst some contain differentiating cells with fewer 
fibrils (astrocytoma protoplasmatica). No attempt has been made in this study to separate the two forms as in many cases it was impossible to obtain material for special staining methods. Sixteen examples of an astrocytoma were encountered, whilst the two most malignant gliomata, the medulloblastoma and the glioblastoma, together totalled the same number (eleven medulloblastomata and six glioblastomata). The astrocytomata were nearly as common in the subtentorial region as the medulloblastomata and glioblastomata together, but it has previously been mentioned that the majority of these benign tumours were situated inacessibly in the pons. In three instances the astrocytomata had the peculiar diffuse distribution designated ' diffuse gliomatosis of the pons.' In the cerebellum and pontocerebellar region the astrocytoma was only half as common as the more malignant forms. Bailey ${ }^{4}$ in a large series found that 50 per cent. of cerebellar tumours were benign astrocytomata.

The occurrence of the malignant glioblastoma multiforme (formerly called 'spongioblastoma multiforme') in six cases was rather surprising. This is predominantly a tumour of adult life and few examples have been recorded in children. Bailey and Cushing $^{5}$ reported that their youngest example was that of a child of twelve years. These tumours are said to occur almost invariably in the cerebral hemispheres (Bailey $\left.{ }^{2}\right)$. Bailey and Cushings found only two in the cerebellum out of seventy-seven examples. As the name suggests, these tumours are remarkable for the polymorphism of their constituent cells. Degenerative changes are common and haemorrhage is frequent. By appropriate staining methods cells resembling phases in development of neuroglial cells from the early unipolar spongioblast to the fully developed astrocyte can be seen, though all stages in development can rarely be found in a single section. The presence of giant cells, often of enormous size, with many lobed nuclei is characteristic. They probably represent an early stage in degeneration. Fig. 3 shows the variation in size of cells and two giant cells in a glioblastoma of the midbrain from a boy of four-and-a-half years, and fig. 4 a huge giant cell in a glioblastoma of the pons in a boy aged seven years. Two of the glioblastomata in this series cccurred in the cerebellum; one in the pons; one involved the pons and the cerebellum; one occupied the whole of the midbrain and one lay in the parietal lobe. The age incidence is given in table 4, but it is noteworthy that one occurred at the early age of fourteen months.

Four examples of ependymal tumours were found. One was small and confined to the fourth ventricle; two apparently occupied the whole of the vermis of the cerebellum and one had grown from the floor of the fourth ventricle into the pons and cerebellum. These tumours occur for the most part in the same situation as the highly malignant medulloblastoma and their differentiation is important as the ependymoma is amenable to surgical treatment whilst the medulloblastoma invariably recurs, even after apparently complete removal. Macroscopically the ependymoma generally appears whiter in colour, is firmer and has a more irregular surface than 


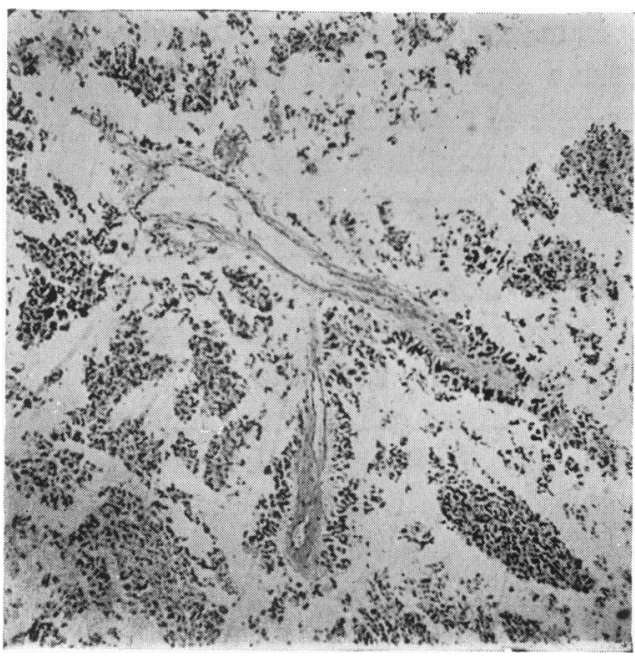

Fig. 1. $x$ 50. - Low -power view of a medullohastoma of cerebellum showing perivascular arrangement of cells with clear space between the cells and the vessel walls. (From a girl aged eleven years.) Stain : iron haematoxylin, Van Gieson.

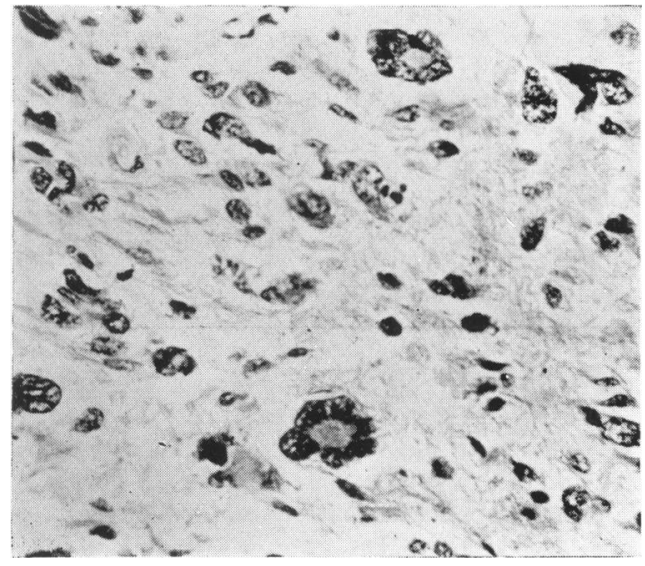

Fig. 3. $\times$ 340.-Section of a gliohlastoma multiforme showing the variation in size and character of the cells. Two giant cells with lobed nuclei are present. (From the micibrain of a boy aged five-and-a-half years.) Stain: haematoxylin, eo-in.

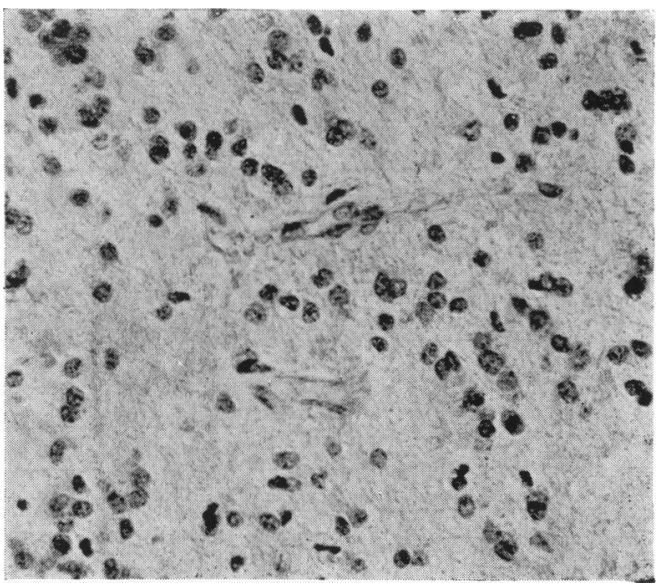

Fig. 2. $x$ 220.--Section of an astrocytoma to show individual cells, all similar. The stroma is formed by fibrillar processis. (From the vermis of the cerebellum of a boy aged twoand-a-half years.) Stain : iron haematoxylin, Van Fieson.

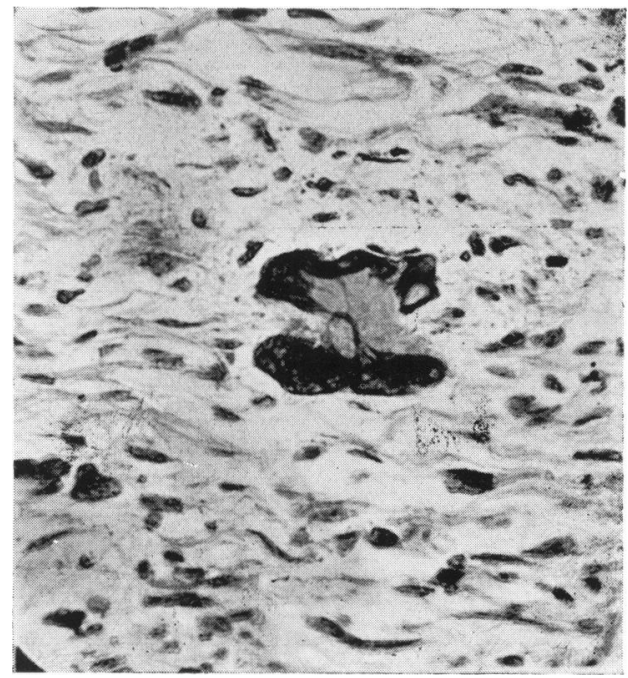

FIi. 4. $\times 320$. - Section of a glioblastoma multiforme. An enormous giant cell undergoing mitosis occupies most of the field. Strands of chromatin can be seen between the dividing, lobed nuclei. (From a tumour of the pons in a boy aged seven years.) Stain : haematoxylin, eosin. 
the medulloblastoma which is reddish-grey in colour, due to its vascularity. Microscopically the cells of the ependymoma are elongated with much cytoplasm prolonged into a thick process which is attached to the wall of a blood vessel. The nuclei are oval and the chromatin is finely divided. The elongated processes attached to blood vessels cause the cells to appear as if they radiate from the vessels. This appearance is described by Bailey as a 'pseudo-rosette' (to distinguish it from the ' true rosette' in which the cells radiate round a cavity lined by epithelium, as in neuroepithelioma of the retina). In the cytoplasm of many of these cells, near the nucleus, a group of small granules or rods may be seen. These granules are known as blepharoplasts and stain by neuroglial methods. Fig. 5 gives the general arrangement of cells in an ependymoma and fig. 6 is a high power view of a pseudo-rosette.

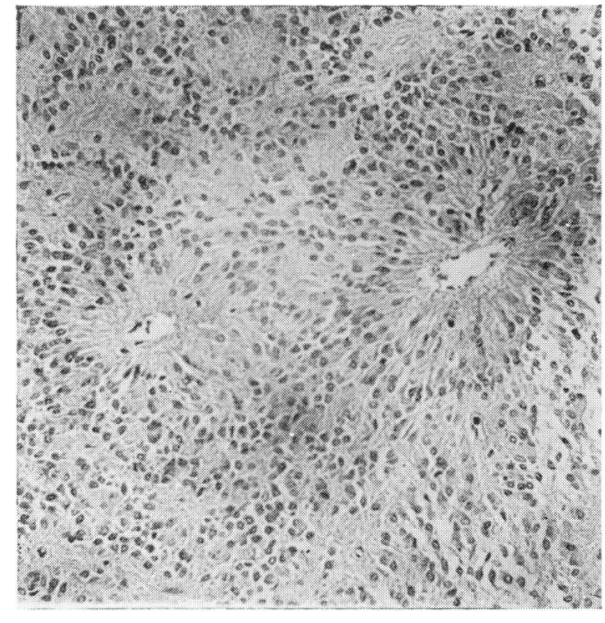

Fic. 5. x 100.-Low-power view of an ependymoma to show general arrangement of cells. Two 'pseudo-rosettes' are present in the field. (From a mid-line tumour of the cerebellum in a girl aged four-and-a-half years.) Stain : haematoxylin, eosIn.

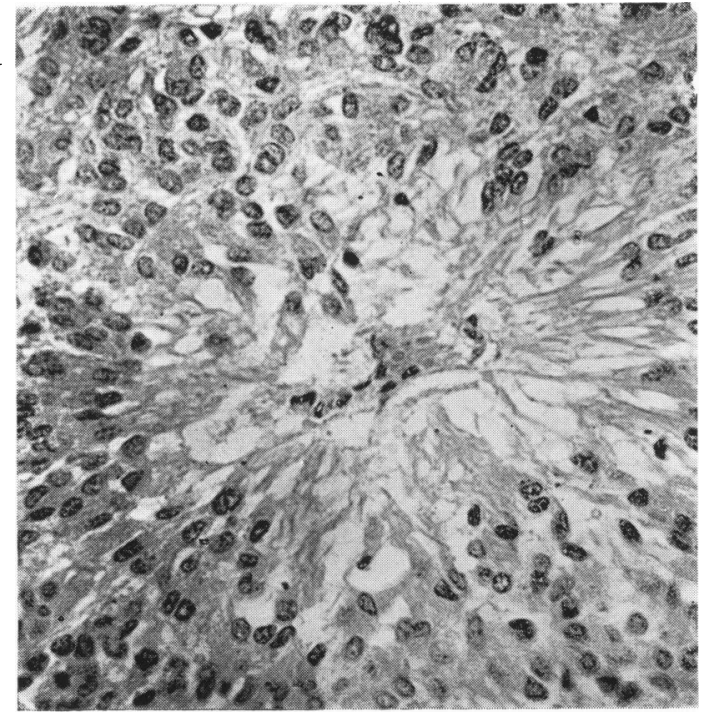

Fic. 6. $x$ 320.-High-power view of a rosette from the same case as fig. 5 . The cells radiate from the walls of the blood vessel to which their elongated processes are attached. Stuin: Mallory's phosphotungstic acid haematoxylin.

The ependymomata are not very uncommon tumours in children. Five out of eight ependymomata in the series reported by Fincher and Coon ${ }^{10}$ were in children under twelve years of age. Their cases were remarkable in that only two occurred in the region of the fourth ventricle; the three others were in the cerebral hemispheres. Gross ${ }^{12}$ in reporting a series of nine cases of cerebral tumour in children under the age of two years was able to include three of ependymoma (one of which, aged one year and four months had previously been described by Fincher and Coon). In the present series there were two cases under the age of two years, one aged only five-and-a-half months, 
The medulloblastomata presented no unusual histological features. These tumours are chiefly composed of small, undifferentiated cells with little cytoplasm, many of which show mitotic figures, but in some parts of the tumour more differentiated cells may be stained by silver impregnation methods. Many of the primitive cells are grouped around clear spaces in which a delicate fibrillar network can be seen (another type of " pseudorosette '), whilst in other areas there is a definite perivascular arrangement of cells, a clear space being present between the cells and the wall of the blood vessel (fig. 1).

One tumour, a rapidly spreading growth of the third ventricle appeared to conform to the description of a spongioblastoma in this region given by Russell and Cairns ${ }^{14}$ and was thus classified.

Four sarcomata occurred in the series. One of these (sarcoma of the occipital lobe in an infant of one year and ten months), was reported by Russell and Ellis ${ }^{13}$. Of the others, two were small round-celled sarcomata, one of which occupied practically the whole of the right frontal lobe and involved the dura extensively, whilst the other appeared to arise in the crura cerebri. Both were apparently primary. The fourth case was one of melanotic sarcoma, and presumably a secondary growth, but unfortunately the autopsy was limited to the brain and no note was made of the condition of the retina.

It was rather remarkable that only one solitary tuberculoma was found. This was a huge mass replacing the whole of the right lobe of the cerebellum. In one other case the mass in the cerebellum was large and only one as big as a pea was present in the right parietal lobe. These two cases and the case in which there was extensive destruction of the basal ganglia were operated upon for decompressions. None of these cases showed a tuberculous meningitis at autopsy. In only two of the six cases of tuberculomata was there a meningitis. In one of these a tuberculomata in the cerebellum was situated at the extreme tip of the posterior pole; in the other, one was present in the floor of the fourth ventricle. This finding does not confirm the assertion of Garland and Armitage ${ }^{11}$ that the cerebral tuberculomata practically only give rise to symptoms when meningitis supervenes.

The age incidence of the various types of tumour was of interest as contrary to what was expected the benign tumours occurred at an earlier age than did the more malignant ones. Eleven out of the sixteen astrocytomata were in children under the age of five years; only two of the medulloblastomata fell into this age period. The actual age incidence of the histological types is given in table 4 . 
TABLE 4.

Age incidence of histologichi, TyPes of TrMours.

\begin{tabular}{|c|c|c|c|c|c|c|c|c|c|c|c|c|}
\hline TYPE OF TUMOUR & $\begin{array}{l}0-1 \\
\text { YR. }\end{array}$ & $\begin{array}{l}1-2 \\
\text { YK. }\end{array}$ & $\begin{array}{l}2-3 \\
\text { Yr. }\end{array}$ & $\begin{array}{l}3-4 \\
\text { VR. }\end{array}$ & $\begin{array}{l}4-\overline{0} \\
\text { Y R. }\end{array}$ & $\begin{array}{l}5-6 \\
\text { YR. }\end{array}$ & $\begin{array}{l}6-7 \\
\text { Yк. }\end{array}$ & $\begin{array}{l}7 \cdot 8 \\
\text { Ik. }\end{array}$ & $\begin{array}{l}8-9 \\
\text { Yk. }\end{array}$ & $\begin{array}{l}9-10 \\
\text { YR. }\end{array}$ & $\begin{array}{c}10-11 \\
\text { YR. }\end{array}$ & $\begin{array}{l}11-12 \\
\text { YR. }\end{array}$ \\
\hline Medulloblastoma ... & 0 & 1 & 1 & 0 & 0 & 1 & 4 & 1 & 1 & 0 & 1 & 1 \\
\hline Glioblastoma & 0 & 1 & 1 & 0 & 0 & 1 & 3 & 0 & 0 & 0 & 0 & 0 \\
\hline 'Mixed glioma' $\ldots$ & 0 & 0 & 1 & 0 & 0 & 0 & 1 & 0 & 0 & 0 & 0 & 0 \\
\hline Spongioblastoma ... & 1 & 0 & 0 & 0 & 0 & 1 & 0 & 0 & 0 & 0 & 0 & 0 \\
\hline Ependymoma & 1 & 0 & 1 & 0 & 1 & 0 & 0 & 0 & 0 & 0 & 1 & 0 \\
\hline Astrocytoma group & 2 & 1 & 2 & 3 & 3 & 2 & 1 & 0 & 1 & 0 & 0 & 1 \\
\hline Meningioma & 0 & 1 & 0 & 1 & 0 & 0 & 0 & 0 & 0 & 0 & 0 & 0 \\
\hline 'Tuberculoma & 2 & 0 & 0 & 1 & 0 & 0 & 0 & 1 & 1 & 1 & 0 & 0 \\
\hline Sarcoma & 0 & 2 & 0 & 1 & 1 & 0 & 0 & 0 & 0 & 0 & 0 & 0 \\
\hline $\begin{array}{l}\text { Epithelioma of } \\
\text { choroid plexus }\end{array}$ & 0 & 0 & 1 & 0 & 0 & 0 & 0 & 0 & 0 & 0 & 0 & 0 \\
\hline
\end{tabular}

\section{Comment}

The main points to which attention was directed were the general incidence of cerebral tumours, the age incidence, the differentiation of histological types and their age incidence. The figures obtained for the autopsy rate was higher than was expected $-2 \cdot 2$ per cent. of all autopsies during the fifteen year period under review being due to cerebral tumours. It was not possible to ascertain accurately the proportion of cases of cerebral tumour to the total admissions for this period. The large proportion of tumours which occurred at an early age was a surprising result and at variance with most of the series hitherto published. One reason for this may be that most of the literature on cerebral tumours in children recently published has come from neurological hospitals which young infants seldom reach. An analysis of the topographical distribution confirmed the observations of others. Twice as many tumours were present below the tentorium as above it. In children therefore the more primitive regions of the brain appear to be affected by tumour rather than the regions more recently evolved. On the same grounds it might be supposed that the tumours present would consist of more primitive, malignant cells than do those of adults. Actually this was not the case in this series. A slow-growing tumour with well-differentiated cells was as common as the more malignant types of tumour derived from nervous tissue. The hopelessness of these cases with benign tumours is due to their situation which all too often offers insuperable difficulties to a surgical approach. They kill by their site of election rather than by their nature or size. It might also be expected that 
the more malignant types of growth would occur at earlier ages than those more benign. This was not so in the present series. The majority of the benign growths occurred before the age of five years, whilst only a small proportion of the malignant gliomata arose before the fifth year.

\section{Summary}

One hundred and two cases of cerebral tumour which occurred during the period 1921 to 1935 in children under the age of twelve years have been investigated. Over one-half of these occurred during the first five years of life. There was no difference in the sex incidence. The sixty-two cases which came to autopsy formed $2 \cdot 2$ per cent. of all post-mortem examinations during that period. Fourteen of the tumours verified at autopsy occurred during the first two years of life. Tumours were twice as common below the tentorium as above it. No tumours of the pituitary fossa were encountered and only one occurred in the suprapituitary region. Unfortunately sections from this tumour were not available. A histological study was made of fifty-five tumours. Two-thirds of these belonged to the glioma group. Well-differentiated gliomata were as common as the more malignant forms but occurred in situations inaccessible to surgical treatment. There were six examples of a malignant glioma, glioblastoma multiforme, a tumour which almost invariably occurs in the cerebral hemispheres of adults. In this series three were found below the tentorium. Four ependymal tumours were included in the series. One of these was in an infant of five-and-ahalf months. The more benign gliomata occurred at an earlier age than did those of greater malignancy. Only one solitary tuberculoma was found. Excluding the small multiple tuberculomata found by careful search in cases of tuberculous meningitis (which are being reported elsewhere and are nct included in this series) tuberculomata were rare tumours. There were only six examples to record, and in four of these (on three of which a decompression operation had been performed during life), there was no evidence of a meningitis either clinically or at autopsy.

My thanks are expressed to the physicians and surgeons of the Hospital for Sick Children for according facilities for this work and for the use of the case and autopsy records. Dr. D. Nabarro, Director of the Pathological Department, has kindly given much encouragement and advice. I am indebted to Dr. Dorothy S. Russell for sending sections of several cases which had been referred to her for diagnosis before this investigation was undertaken and for kindly allowing the use of her reports on them; to Dr. J. G. Greenfield for the same courtesy and also for his generous help in interpreting some of the more difficult tumours. Mr. Deryck Martin patiently devoted much time to taking the photomicrographs, the apparatus with which these were taken being purchased by the aid of a grant from the Thomas Smythe Hughes Fund. 


\section{REFERENGIS}

1. Armour, D., Lancet, London, 1932, ii, 551.

2. Bailey, P., Arch. Path., Chicago, 1927, IV, 871.

3. Idem, Arch. Neurol. \& Psychiat., Chicago, 1932, XXVII, 1290.

4. Idem, 'Intracranial Tumours,' London, 1933.

5. Bailey, P., \& Cushing, H., ' Tumours of the Glioma Group,' Philadelphia, 1926.

6. Blacklock, J. W. S., Trans. Med. Chirg. Soc. Glasgow, Glasgow, 1934, XXVIII, 127.

7. Critchley, M., Brit. J. Child. Dis., London, 1925, XXII, 251.

8. Cushing, H., Am. J. Dis. Child., Chicago, 1927, XXXIII, 551.

9. Idem, Acta. Path. et Microbiol. Scan., Copenhagen, 1930, VII, 1.

10. Fincher, E. F., \& Coon, G. P., Arch. Neurol. \& Psychiat., Chicago, 1929, XXII, 19.

11. Garland, H., \& Armitage, G., J. Path. \& Bact., Edinburgh, 1933, XXXVII, 461.

12. Gross, S. W., Am. J. Dis. Child., Chicago, 1934, XLVIII, 739.

13. Russell, D. S., \& Ellis, R., Arch. Dis. Childh., London, 1933, VIII, 329.

14. Russell, D. S., \& Cairns, H., Brain, London, 1931, LIV, 377.

15. Scott, E., \& Graves, G. O., Am. Rev. Tuberc., New York, 1933, XXVII, 171.

16. Starr, A., 'Nervous Diseases,' New York, 1908.

17. Van Wagenen, W. P., Arch. Neurol. \& Psychiat., Chicago, 1927, XVII, 57.

18. Wollstein, M., \& Bartlett, F. H., Am. J. Dis. Child., Chicago, 1923, XXV, 257.

19. Wyllie, W. G., J. Neurol. Psychopath., London, 1924, V, 209. 